\title{
PENGARUH KEPUASAN KONSUMEN, HARGA, KUALITAS PRODUK, DAN PROMOSI TERHADAP LOYALITAS MEREK ALAT ANGKAT / CRANE XYZ PADA PT.ABC
}

\author{
Tommy \\ Program Studi Magister Manajemen Universitas Tarumanagara \\ Tommy.Sukanto@gmail.com
}

\begin{abstract}
The research aims to determine the effect of customer satisfaction, price, product quality and promotion of brand loyalty of PT ABC lifting equipment (crane). The tool used to obtain the data is a questionnaire using Likert scale. Sampling technique is purposive sampling that is technique of determining sample with certain consideration. The sample in this research is some of PT.ABC consumers in Indonesia which amounted to 50 people, but only 43 respondents who answered this questionnaire. The results show that customer satisfaction has a significant influence on brand loyalty, while price, product quality and promotion have no significant effect on brand loyalty.
\end{abstract}

Keywords : brand loyalty, customer satisfaction, price, product quality, promotion

\section{PENDAHULUAN}

Belanja pemerintah pada 2016 memiliki kaitan erat dengan program - program pemerintahan yang berbasis pada pembangunan / sektor konstruksi. Berbagai program seperti tol laut, pembangunan daerah perbatasan, infrastruktur jalan daerah terluar Indonesia maupun infrastruktur kota dan antar propinsi terus dipacu pengerjaanya agar mencapai target program pemerintah.

Melihat potensi pasar yang sangat luas, apalagi didukung dengan program pemerintah, bermacam - macam sektor yang membutuhkan alat angkat / crane tersebut antara lain konstruksi, sumber daya mineral, sumber daya minyak dan gas, ekspedisi, pelabuhan, rental, dan perkapalan. Sebagai salah satu distributor alat - alat konstruksi seperti alat angkat / crane , generator set, Diesel Pile Hammer, dan alat konstruksi lainnya, maka PT. ABC selalu menyediakan produk dan jasa yang terbaik. Khususnya pada produk unggulan atau produk premium PT. ABC yaitu alat angkat / crane dengan merek XYZ. Disamping itu berbagai model alat angkat / crane yang ditawarkan juga sangat beragam, sehingga dalam aplikasi dilapangan dapat disesuaikan, antara lain mobile crane, crawler crane, rough terrain crane, dan mounted crane.

Beragam jenis merek yang ada di pasaran, menyebabkan setiap perusahaan harus melakukan kajian dan strategi yang tepat untuk memenangkan hati konsumen, yang pada akhirnya adalah mendapatkan keputusan konsumen dalam membeli suatu produk. Produk yang dibeli oleh konsumen / pelanggan harus dijaga dengan baik sehingga akan memberikan kepuasan yang sesuai ekspektasi, bahkan melebihi ekspektasi. Jika pelanggan sudah merasa puas dengan produk dan jasa yang kita jual, barulah rasa loyalitas akan muncul atas produk tersebut. Hill (2014) konsep brand loyalty (loyalitas merek) melibatkan pembelian produk dari produsen tunggal berulang kali daripada membeli dengan suppliers(pemasok) lain. Menurut Zehir, et al (2011) brand loyalty merupakan prasyarat untuk daya saing perusahaan dan profitabilitas. Faktor faktor yang mempengaruhi loyalitas merek alat angkat (crane) pada PT ABC dalam penelitian ini difokuskan pada kepuasan pelanggan, harga, kualitas produk dan promosi. 


\section{TUJUAN PENELITIAN}

Fokus utama dari penelitian ini adalah untuk mengetahui pengaruh kepuasan pelanggan, harga, kualitas produk, dan promosi terhadap loyalitas merek alat angkat / crane XYZ pada PT.ABC.

\section{TINJAUAN PUSTAKA}

1. Pengaruh Kepuasan Konsumen Terhadap Loyalitas Merek

Kesetiaan merek terbentuk melalui proses pembelajaran, yaitu suatu proses dimana konsumen melalui pengalamannya berusaha mencari merek yang paling sesuai untuknya, dalam arti produk dari merek tersebut dapat memberikan kepuasan yang sesuai dengan harapan dan kebutuhannya. Konsumen akan terus menerus mencoba berbagai macam merek sebelum menemukan merek yang benar-benar cocok.

Kepuasan konsumen akan tetap merupakan bagian yang sangat penting dalam kesetiaan merek. Kesetiaan merek biasanya mengakibatkan repeat buying dan recommended buying. Jika konsumen puas akan performance suatu merek maka akan membeli terus merek tersebut, menggunakannya bahkan memberitahukan pada orang lain akan kelebihan merek tersebut berdasarkan pengalaman konsumen dalam memakai merek tersebut. Jika konsumen puas akan suatu merek tertentu dan sering membeli produk tersebut maka dapat dikatakan tingkat kesetiaan merek itu tinggi, sebaliknya jika konsumen tidak terlalu puas akan suatu merek tertentu dan cenderung untuk membeli produk dengan merek yang berbeda-beda maka tingkat kesetiaan merek rendah.

Penelitian Abdul(2014) membuktikan bahwa kepuasan konsumen berpengaruh positif signifikan terhadap loyalitas merek. Hal ini didukung oleh Widyastuti, (2013), dan Azizah (2016), serta Lee, Hsu, Fu, (2013).

\section{Pengaruh Harga Terhadap Loyalitas Mrek}

Harga adalah salah satu faktor yang mempengaruhi kebanyakan orang dalam menentukan pilihan pada suatu pembelian produk. Sebagai salah satu faktor yang mempengaruhi, harga terkadang menjadi sangat tidak terkendali seperti perang harga. Berbagai supplier atau penjual sangat mempertimbangkan faktor harga, apakah lebih murah dari competitor dan sebagainya. Karena bagaimanapun konsumen akan menggunakan pertimbangan nalar dalam menentukan pilihan terhadap suatu produk. Apakah produk tersebut sesuai dengan nilai uang yang mereka keluarkan, ataukah berlebihan (overvalue).

Beberapa penelitian menunjukan bahwa harga memiliki pengaruh positif signifikan terhadap loyalitas merek antara lain Pordehghan, (2015), Dhurup, et al (2014), danIndrayani, et al(2011).

3. Pengaruh Kualitas Produk Terhadap Loyalitas Merek

Dalam membeli suatu produk, konsumen pasti mengharapkan kualitas produk yang sesuai dengan ekspektasi atau harapan lebih akan produk tersebut. Namun kenyataannya terkadang konsumen menghadapi hal yang berlawanan dan tak jarang kecewa atas produk yang mereka beli. Sebaliknya, kualitas produk yang baik akan memberikan kesan atau dampak secara langsung terhadap konsumen. Hal ini menunjukan baik atau buruknya kualitas suatu produk dapat mempengaruhi keputusan konsumen agar loyal dalam menggunakan suatu produk. 
Penelitian pengaruh kualitas produk terhadap loyalitas merek didukung oleh penelitian Wolfling $(2013 ; 2015)$. Penelitian signifikan positif tersebut juga didukung oleh Budiman, et al (2013) dan Khan, et al (2015)

4. Pengaruh Promosi Terhadap Loyalitas Merek

Berbagai macam produk baik barang maupun jasa, membutuhkan strategi-strategi tertentu agar produk tersebut dapat dilirik oleh konsumen atau dibeli oleh konsumen. Selain kualitas dan harga, strategi promosi yang baik dan benar, akan sangat efektif apabila implementasi strategi di lapangan tepat sasaran dan sesuai dengan segmentasi dan positioning produk tersebut. Hal ini dapat memudahkan produk itu sendiri agar dikenal lebih baik oleh masyarakat. Terkadang modifikasi produk diperlukan untuk memberikan penyegaran inovasi terhadap produk tersebut. Karena dengan modifikasi, maka akan terlihat differensiasi sebagai nilai lebih dibanding produk lain.

Promosi berpengaruh dengan loyalitas merek, hal ini ditunjukan dengan penelitian sebelumnya yang dilakukan oleh Bangkang \&Tawas(2015) dan Pordehghan (2015)

Di bawah ini disajikan rangkuman penelitian terdahulu

\section{Penelitian Terdahulu}

\begin{tabular}{|c|c|c|c|c|c|}
\hline No & Tahun & Peneliti & Variabel Y & Variabel X & Hasil \\
\hline 1 & 2017 & $\begin{array}{l}\text { I Putu Surya Ananta } \\
\text { Wijaya, I Nyoman } \\
\text { Nurcaya }\end{array}$ & $\begin{array}{l}\text { Loyalitas } \\
\text { Merek }\end{array}$ & $\begin{array}{l}\text { Kepuasan } \\
\text { Pelanggan, } \\
\text { Kualitas } \\
\text { Produk }\end{array}$ & $\begin{array}{l}\text { Signifikan } \\
\text { (Kepuasan } \\
\text { Pelanggan, Kualitas } \\
\text { Produk) }\end{array}$ \\
\hline 2 & 2016 & Luluk Nur Azizah & $\begin{array}{l}\text { Loyalitas } \\
\text { Merek }\end{array}$ & $\begin{array}{l}\text { Kepuasan } \\
\text { Konsumen }\end{array}$ & $\begin{array}{ll}\text { Signifikan } & \text { Positif } \\
\text { (Kepuasan } & \\
\text { Konsumen) } & \end{array}$ \\
\hline 3 & 2015 & $\begin{array}{l}\text { Mula Nazar Khan, } \\
\text { Zain-ul-Aabdean, } \\
\text { Muhammad Salman, } \\
\text { Babar Nadeem, } \\
\text { Muhammad Rizwan }\end{array}$ & $\begin{array}{l}\text { Brand } \\
\text { Loyalty }\end{array}$ & $\begin{array}{l}\text { Product, } \\
\text { Service } \\
\text { Quality }\end{array}$ & $\begin{array}{l}\text { Positive } \\
\text { (Product, } \\
\text { Quality) }\end{array}$ \\
\hline 4 & 2015 & Adel Pourdehghan & $\begin{array}{l}\text { Brand } \\
\text { Loyalty }\end{array}$ & $\begin{array}{l}\text { Marketing } \\
\text { Mix(Price, } \\
\text { Place, } \\
\text { Product, } \\
\text { Promotion) }\end{array}$ & $\begin{array}{l}\text { Positive Significant } \\
\text { (Marketing Mix) }\end{array}$ \\
\hline 5 & 2015 & $\begin{array}{l}\text { Angel Stefanie } \\
\text { Bangkang, } \\
\text { Hendra N. Tawas }\end{array}$ & $\begin{array}{l}\text { Loyalitas } \\
\text { Merek }\end{array}$ & $\begin{array}{l}\text { Brand } \\
\text { Awareness, } \\
\text { Promosi }\end{array}$ & $\begin{array}{l}\text { Signifikan Positif } \\
\text { (Brand Awareness, } \\
\text { Promosi) }\end{array}$ \\
\hline 6 & 2015 & $\begin{array}{l}\text { MARTINA } \\
\text { FERENČIĆ, } \\
\text { ANA WÖLFLING }\end{array}$ & $\begin{array}{l}\text { Brand } \\
\text { Loyalty }\end{array}$ & $\begin{array}{l}\text { Negative } \\
\text { Quality }\end{array}$ & $\begin{array}{l}\text { Positive Significant } \\
\text { (Negative Quality) }\end{array}$ \\
\hline 7 & 2014 & $\begin{array}{l}\text { Prof.Dr.Abdul } \\
\text { Ghafoor Awan, } \\
\text { Asad-ur Rehman }\end{array}$ & $\begin{array}{l}\text { Brand } \\
\text { Loyalty }\end{array}$ & $\begin{array}{l}\text { Customer } \\
\text { Satisfaction }\end{array}$ & $\begin{array}{l}\text { Positive Significant } \\
\text { (Customer } \\
\text { Satisfaction) }\end{array}$ \\
\hline 8 & 2014 & Zohaib Ahmed & $\begin{array}{l}\text { Brand } \\
\text { Loyalty }\end{array}$ & $\begin{array}{l}\text { Brand Trust, } \\
\text { Customer }\end{array}$ & $\begin{array}{l}\text { Positive Significant } \\
\text { (Brand Trust , }\end{array}$ \\
\hline
\end{tabular}




\begin{tabular}{|c|c|c|c|c|c|}
\hline & & & & & Satisfaction) \\
\hline 9 & 2014 & $\begin{array}{l}\text { Manilall Dhurup, } \\
\text { Chengedzai Mafini, } \\
\text { Tshepiso Dumasi }\end{array}$ & $\begin{array}{l}\text { Brand } \\
\text { Loyalty }\end{array}$ & $\begin{array}{l}\text { Packaging, } \\
\text { Price, Brand } \\
\text { Awareness }\end{array}$ & $\begin{array}{l}\text { Positive Significant } \\
\text { (Packaging, Price, } \\
\text { Brand Awareness) }\end{array}$ \\
\hline 10 & 2013 & $\begin{array}{ll}\text { Dicky } & \text { Budiman, } \\
\text { Hastuti } & \text { Naibaho, } \\
\text { Amelia } & \end{array}$ & $\begin{array}{l}\text { Kesetiaan } \\
\text { Merek }\end{array}$ & $\begin{array}{l}\text { Kualitas } \\
\text { Layanan, } \\
\text { Kualitas } \\
\text { Produk, } \\
\text { Kepuasan } \\
\text { Pelanggan }\end{array}$ & $\begin{array}{lr}\text { Signifikan } & \text { Positif } \\
\text { (Kualitas } & \text { Layanan, } \\
\text { Kualitas } & \text { Produk, } \\
\text { Kepuasan } & \\
\text { Pelanggan) } & \end{array}$ \\
\hline 11 & 2013 & $\begin{array}{l}\text { Kuan-Yin Lee, Yin- } \\
\text { Chieh Hsu, Shan- } \\
\text { Heng Fu }\end{array}$ & $\begin{array}{l}\text { Brand } \\
\text { Loyalty }\end{array}$ & $\begin{array}{l}\text { Service } \\
\text { Convinience, } \\
\text { Satisfaction, } \\
\text { Commitment }\end{array}$ & $\begin{array}{l}\text { Positive Significant } \\
\text { (Service } \\
\text { Convinience, } \\
\text { Satisfaction, } \\
\text { Commitment) }\end{array}$ \\
\hline 12 & 2013 & $\begin{array}{l}\text { Martina Ferenčić, } \\
\text { Ana Wölfling }\end{array}$ & $\begin{array}{l}\text { Brand } \\
\text { Loyalty }\end{array}$ & $\begin{array}{l}\text { Product } \\
\text { Quality }\end{array}$ & $\begin{array}{l}\text { Positive Significant } \\
\text { (Product Quality) }\end{array}$ \\
\hline 13 & 2013 & $\begin{array}{l}\text { Azizah Ami } \\
\text { Widyastuti }\end{array}$ & $\begin{array}{l}\text { Loyalitas } \\
\text { Merek }\end{array}$ & $\begin{array}{l}\text { Kepuasan } \\
\text { Konsumen }\end{array}$ & $\begin{array}{ll}\text { Signifikan } & \text { Positif } \\
\text { (Kepuasan } & \\
\text { Konsumen) } & \\
\end{array}$ \\
\hline 14 & 2012 & $\begin{array}{l}\text { Emmy Indrayani, } \\
\text { Hotniar } \\
\text { Siringoringo, } \\
\text { Trini Saptariani }\end{array}$ & $\begin{array}{l}\text { Brand } \\
\text { Loyalty }\end{array}$ & Price & $\begin{array}{l}\text { Positive Significant } \\
\text { (Price) }\end{array}$ \\
\hline 15 & & $\begin{array}{l}\text { Selamat Zebua, Dion } \\
\text { Dewa Barata }\end{array}$ & $\begin{array}{l}\text { Loyalitas } \\
\text { Merek }\end{array}$ & $\begin{array}{l}\text { Kualitas } \\
\text { Merek, } \\
\text { Persepsi } \\
\text { Merek, } \\
\text { Inovasi }\end{array}$ & $\begin{array}{ll}\text { Signifikan } & \text { Positif } \\
\text { (Kualitas } & \text { Merek, } \\
\text { Persepsi } & \text { Merek, } \\
\text { Inovasi) } & \end{array}$ \\
\hline
\end{tabular}

\section{METODE PENELITIAN}

Teknik pengumpulan data yang digunakan dalam penelitian ini adalah dengan menggunakan angket atau kuesioner. Teknik pengambilan sampel adalah purposive sampling yaitu "Teknik penentuan sampel dengan pertimbangan tertentu". (Sugiyono, 1999). Sampel pada penelitian ini yaitu sebagian konsumen PT.ABC di seluruh Indonesia yang berjumlah 50 orang, tetapi hanya 43 responden yang menjawab kuesioner ini. Alat yang digunakan untuk mengumpulkan data adalah angket dimana alternatif jawaban dari pertanyaan telah disediakan. Sedangkan untuk pengukurannya menggunakan skala likert. Menurut Sugiono (2006 : 107) "Skala likert adalah skala yang digunakan untuk mengukur sikap, pendapat, dan persepsi seseorang atau sekelompok orang tentang fenomena sosial". 
HASIL DAN KESIMPULAN

1. Hasil Uji F

ANOVA $^{\text {a }}$
\begin{tabular}{|l|l|l|l|l|l|}
\hline Model & Sum of Squares & df & Mean Square & F & Sig. \\
\hline 1 Regression & 5 & 4 & 17,936 & 5,457 &, $001^{\text {b }}$ \\
Residual & 124,906 & 38 & 3,287 & & \\
Total & 196,651 & 42 & & & \\
\hline
\end{tabular}

Dari tabel di atas dapat dilihat bahwa nilai signifikannya adalah sebesar 0,001 atau lebih kecil dari nilai $\alpha=0,05$ jadi hipotesis tidak ditolak, artinya paling sedikit ada satu variable yang mempengaruhi variable $\mathrm{Y}$ dengan tingkat keyakinan diatas $95 \%$.

\section{Hasil Uji R square}

Model Summary

\begin{tabular}{|l|l|l|l|l|l|}
\hline Model & R & R Square & $\begin{array}{l}\text { Adjusted R R } \\
\text { Square }\end{array}$ & $\begin{array}{l}\text { Std. Error of } \\
\text { the Estimate }\end{array}$ & $\begin{array}{l}\text { Durbin- } \\
\text { Watson }\end{array}$ \\
\hline 1 &, $604^{\mathrm{a}}$ &, 365 &, 298 & 1,81301 & 1,555 \\
\hline
\end{tabular}

a. Predictors: (Constant), Kepuasan Pelanggan, Harga, Kualitas Produk, Promosi

b. Dependent Variable: Loyalitas Merek

Sumber : Data kuesioner yang telah diolah oleh data SPSS 19.0 untuk windows

Nilai $\mathrm{R}^{2}$ pada tabel di atas menginformasikan bahwa koefisien determinasi yang didapat dari hasil pengolahan data sebesar $0,365\left(\mathrm{R}^{2}=0,365\right)$ atau sebesar $36,5 \%$, artinya bahwa $36,5 \%$ dari proporsi variabel loyalitas merek dapat dijelaskan oleh kepuasan konsumen, harga, kualitas produk, dan promosi. Sedangkan sisanya sebesar 63,5\% dari proporsi variabel loyalitas merek dapat dijelaskan oleh variable-variabel yang tidak diteliti dalam penelitian ini.

\section{Pengujian Hipotesis}

\section{Hasil Uji t}

\begin{tabular}{|c|c|c|c|c|c|c|}
\hline \multirow{2}{*}{\multicolumn{2}{|c|}{ odel }} & \multicolumn{2}{|c|}{$\begin{array}{l}\text { Unstandardized } \\
\text { Coefficients }\end{array}$} & \multirow{2}{*}{$\begin{array}{l}\text { Standardized } \\
\text { Coefficients } \\
\text { Beta }\end{array}$} & \multirow[b]{2}{*}{$\mathrm{t}$} & \multirow[b]{2}{*}{ Sig. } \\
\hline & & B & Std. Error & & & \\
\hline \multirow[t]{5}{*}{1} & (Constant) & 2,716 & 2,615 & & 1,038 &, 306 \\
\hline & Kepuasan Pelanggan & ,316 & , 162 & ,321 & 1,954 & ,048 \\
\hline & Harga & ,091 & ,122 & ,117 & ,743 & ,462 \\
\hline & Kualitas Produk & ,205 & ,200 &, 150 & 1,025 & ,312 \\
\hline & Promosi & ,209 & ,139 & ,215 & 1,505 & ,141 \\
\hline
\end{tabular}

Dependent Variabel : Loyalitas merek 
Hasil Uji Hipotesis Penelitian

\begin{tabular}{|l|l|l|l|}
\hline Hipotesis & Pernyataan & $\begin{array}{l}\text { Nilai } \\
\text { Signifikansi }\end{array}$ & Keputusan \\
\hline Ha1 & $\begin{array}{l}\text { Ada pengaruh kepuasan pelanggan } \\
\text { terhadap loyalitas merek }\end{array}$ & 0,048 & Diterima \\
\hline Ha2 & $\begin{array}{l}\text { Ada pengaruh harga terhadap } \\
\text { loyalitas merek }\end{array}$ & 0,462 & Ditolak \\
\hline Ha3 & $\begin{array}{l}\text { Ada pengaruh kualitas produk } \\
\text { terhadap loyalitas merek }\end{array}$ & 0,312 & Ditolak \\
\hline Ha4 & $\begin{array}{l}\text { Ada pengaruh promosi terhadap } \\
\text { loyalitas merek } 0,141\end{array}$ & Ditolak \\
\hline
\end{tabular}

\section{Kesimpulan dan Implikasi}

Faktor yang berpengaruh positif signifikan terhadap loyalitas merek adalah kepuasan pelanggan, sementara faktor lain yaitu harga, kualitas produk dan promosi tidak berpengaruh signifikan terhadap loyalitas merek alat angkat (crane) PT ABC. Dari hasil tersebut dapat disarankan perusahaan dapat menjaga loyalitas merek jika kepuasan pelanggan dapat ditingkatkan. Hal ini dapat dicapai jika konsumen merasa bahwa crane XYZ memiliki ketahanan produk yang baik.

\section{DAFTAR PUSTAKA}

Adisumarto, Harsono. 1990. Hak Milik Intelektual. Khususnya Hak Cipta. Jakarta: CV Akademika Pressindo.

Aaker, David. (1997). Manajemen Ekuitas Merek. Jakarta: Spektrum.

Boyd, Walker, Larreche.2000. Manajemen Pemasaran Suatu Pendekatan Strategis dengan Orientasi Global Edisi 2 Jilid 1. Jakarta: Erlangga.

Buchari Alma, 2004, Manajemen Pemasaran dan Pemasaran Jasa, Alfabeta, Bandung

Cooper, Donald R., \& Schindler, Pamela S. (2011). Business research methods (11th ed.). New York: Mc GrawHill/Irwin.

Kotler, Philip. 2005. Manajamen Pemasaran, Jilid 1 dan 2. Jakarta: PT. Indeks Kelompok Gramedia.

Priyatno, 2012. Cara Kilat Belajar Analisis Data dengan SPSS 20. Edisi kesatu. Yogyakarta : ANDI

Sahin, A; Zehir, C; and Kitapci, H. 2012. The Effect of Brand Experience and Service Quality on Repurchase Intention: the Role of Brand Relationship Quality. African Journal of Business Management.Vol. 6 No.45, 11190-11201.

Sugiyono. 1999. Metodologi Penelitian Administrasi. Edisi Kedua. Bandung: CV Alfa Beta.

Sugiono, (2006). Metode Penelitian Bisnis. Bandung. Alfabeta

Tjiptono, Fandy. 2003. Strategi Pemasaran. Edisi Kedua. Yogyakarta: Andi Offset.

Zaltman, Gerald, dan Wallendorf, Melanie., Consumer Behavior, Second Edition, Englewood Cliffs, New Jersey, Prentice Hall, 1979. 


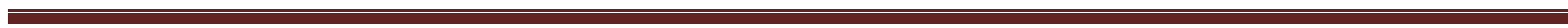
$\cdot$ 